\title{
Penentuan Strategi Pengembangan Website Perguruan Tinggi Menggunakan Quality Function Deployment
}

\author{
Nur Indrianti ${ }^{1}$, Ariez Rizqullah ${ }^{2}$ \\ ${ }^{1}$ Jurusan Teknik Industri, Universitas Pembangunan Nasional "Veteran" Yogyakarta \\ Jl. Babarsari 2, Tambakbayan, Yogyakarta 55281, Indonesia \\ ${ }^{2}$ PT Mitsubishi Jaya Elevator and Escalator \\ Gedung Jaya $11^{\text {th }}$ Floor, Jalan M.H. Thamrin No. 12, Jakarta Pusat 10340, Indonesia \\ Email: n.indrianti@upnyk.ac.id ${ }^{1 *}$; ariezrizqullah@,hotmail.com ${ }^{2}$ \\ *corresponding author
}

\begin{abstract}
The global market environment has made higher education institutions competitive, so higher education institutions should be able to create the right promotional strategies. One strategy that can be applied is integrated marketing communication (IMC) based on a social media website. This research aims to find effective college website development strategies using the Quality Function Deployment (QFD) method. This research uses quantitative and qualitative methods with the concept of QFD. Data collection techniques are conducted with interviews and snowball sampling, and the subject of the study is the website of the National Development University "Veteran" Yogyakarta. Data analysis is done with Crosstabs data reduction techniques and data display. The results showed that the QFD method, which integrates consumer voice and technical aspects, can be used to determine college website development strategies that can improve the effectiveness of websites as IMC media while improving webometrics ranking. The strategy can improve the quality of the website on an ongoing basis. This research provides recommendations to other universities or other institutions to maximize website development following the quality and needs of consumers. Keywords: Higher Education; Integrated Marketing Communication (IMC); Quality Function Deployment (QFD); Webometrics; Website
\end{abstract}

Lingkungan pasar global telah menjadikan institusi pendidikan tinggi bersaing dengan ketat, sehingga institusi pendidikan tinggi harus dapat menciptakan strategi promosi yang tepat. Salah satu strategi yang dapat diterapkan adalah komunikasi pemasaran terpadu (Integrated Marketing Communication, IMC) berbasis media sosial website. Penelitian ini bertujuan untuk menemukan strategi pengembangan website perguruan tinggi yang efektif menggunakan metode Quality Function Deployment (QFD). Penelitian ini menggunakan metode kuantitatif dan kualitatif dengan konsep QFD. Teknik pengumpulan data dilakukan dengan wawancara dan snowball sampling, dan subjek penelitian adalah website Universitas Pembangunan Nasional "Veteran" Yogyakarta. Analisis data dilakukan dengan teknik reduksi data Crosstabs dan tampilan data. Hasil penelitian menunjukkan bahwa metode QFD, yang mengintegrasikan suara konsumen dan aspek teknis, dapat digunakan untuk menentukan strategi pengembangan website perguruan tinggi yang dapat meningkatkan efektivitas website sebagai media IMC sekaligus meningkatkan peringkat Webometrics. Strategi tersebut dapat meningkatkan mutu website secara berkelanjutan. Penelitian ini memberikan rekomendasi kepada perguruan tinggi lain ataupun instansi lain untuk memaksimalkan pengembangan website sesuai dengan mutu dan kebutuhan konsumen. Kata Kunci: Perguruan Tinggi; Komunikasi Pemasaran Terpadu (IMC); Quality Function Deployment (QFD); Webometrics; Website

\section{Pendahuluan}

Institusi pendidikan tinggi saat ini menghadapi tantangan yang semakin kompleks (Simões \& Soares, 2010). Pendidikan yang dulu dianggap sebagai barang publik diselenggarakan oleh organisasi nirlaba dan memiliki misi sosial yang jelas, sekarang telah menjadi pasar global yang ramai dengan dilaksanakan oleh perusahaan semu di pasar pengetahuan (Pucciarelli \& Kaplan, 2016). Lingkungan yang semakin global, digital, dan dinamis menjadikan persaingan lembaga pendidikan tinggi semakin kompetitif dalam memperebutkan pasar mahasiswa. Persaingan pasar dilakukan dengan melakukan manajemen pemasaran yang tepat. 
Sudah lama diakui dalam lingkungannya bahwa manajemen pemasaran bahwa komunikasi pemasaran terpadu (Integrated Marketing Communication, IMC) merupakan strategi promosiyangefektif.Strategiinimengembangkan pendekatan komunikasi pemasaran berdasarkan pada fakta bahwa pelanggan semakin terekspos terhadap pesan-pesan multichannel (Finne \& Grönroos, 2017). IMC mengoordinasikan elemen-elemen bauran promosi, yang terdiri dari periklanan, penjualan pribadi, hubungan masyarakat, publisitas, pemasaran langsung, and promosi penjualan (Boone \& Kurtz, 2007), dan dilakukan secara hati-hati sehingga informasi dapat disampaikan kepada pelanggan secara konsisten dan dikomunikasikan dalam pesan yang terpadu (Mangold \& Faulds, 2009; Finne \& Grönroos, 2017). Seiring dengan munculnya media berbasis Internet, media sosial telah muncul sebagai media komunikasi yang kuat di seluruh dunia. Penggunaannya yang luas telah secara signifikan mengubah cara orang berkomunikasi dan berinteraksi online (Kumar \& Nanda, 2018; Mangold \& Faulds, 2009). Dengan berbagai bentuk konten online-nya media yang berbasis Internet ini memungkinkan organisasi untuk berkomunikasi langsung dengan konsumen secara cepat tanpa ada kendala geografis (Scott, 2015; Štefko et al., 2015).

Konsumen telah menjadikan media sosial sebagai sumber informasi yang lebih dipercaya terkait produk dan jasa daripada elemen-elemen tradisional bauran promosi (Foux, 2006). Media sosial telah menjadikan konsumen berpaling dari sumber periklanan tradisional seperti radio, televisi, majalah, dan koran (Rashtchy et al., 2007 dan Vollmer \& Precourt, 2008, dalam Mangold \& Faulds, 2009). Dilihat dari aspek penggunaan maupun popularitas, media sosial baru atau unmeasured media seperti situs web (website), email, blog, video, portal Microsite, buletin email, Wiki, forum diskusi Internet, forum penilaian produk atau layanan konsumen, dan media sosial lain terus meningkat pertumbuhannya (Shankar \& Hollinger, 2007 dalam Ailawadi et al., 2009; Keegan \& Green, 2008; Belch \& Belch, 2007; Mangold \& Faulds, 2009). Kualitas situs web dapat mempengaruhi persepsi kesenangan dan persepsi pelanggan yang berpengaruh terhadap kepuasan dan niat beli pelanggan (Hsu et al., 2012). Hal ini mengurangi kepraktisan komunikasi tradisional dan menuntut pengembangan strategi IMC, khususnya paradigma komunikasi baru yang berbasis Internet. Terkait hal tersebut media sosial diusulkan sebagai komponen hibrida dari bauran promosi dan dengan demikian dimasukkan sebagai bagian integral dari strategi IMC organisasi (Mangold \& Faulds, 2009).

Lembaga pendidikan tinggi di seluruh dunia sudah mulai menggunakan media sosial untuk berinteraksi dengan calon mahasiswa, mahasiswa, alumni, dan pemangku kepentingan lainnya. Selain untuk meningkatkan komunikasi dan pengembangan berbagai proses, media sosial digunakan oleh perguruan tinggi untuk kegiatan promosi (Kumar \& Nanda, 2018). Institusi pendidikan tinggi menjadikan web sebagai bagian penting dari proses pendidikan (Manzoor et al., 2012). Web dapat menjadi strategi terbuka bagi pendidikan secara online, transfer pengetahuan (dalam bentuk paten, link universitas-bisnis) untuk saling melengkapi penelitian (Kousha \& Thelwall, 2008; Thelwall \& Kousha, 2008) dan memberikan informasi untuk calon siswa (Manzoor et al., 2012). Pelbagai perguruan tinggi secara umum dan perpustakaan akademik khususnya sudah menawarkan informasi dan layanan kepada konsumen atau pengguna melalui berbagai saluran web termasuk kampus virtual, forum diskusi, berita, email, dan lain-lain.

Website juga telah menjadi salah satu dasar pemeringkatan universitas tingkat dunia yang dilakukan oleh Webometrics (Webometrics Ranking of World Universities). Tujuan utama Webometrics adalah mempromosikan publikasi web perguruan tinggi sebagai bentuk dukungan inisiatif akses terbuka serta akses elektronik 
ke publikasi ilmiah dan materi akademik lainnya. Hal ini diharapkan dapat memotivasi lembaga dan akademisi untuk mempublikasikan aktivitas-aktivitas yang dilakukan di web secara akurat (Webometrics, 2018).

Webometrics diinisiasi oleh Cybermetrics Lab, sebuah kelompok riset milik Consejo Superior de Investigaciones Cientificas (CSIC), yaitu sebuah badan penelitian publik terbesar di Spanyol mulai tahun 2004. Melalui Webometrics SCIS melakukan analisis kuantitatif didasarkan pada pendekatan yang mempertimbangkan berbagai kegiatan ilmiah di situs akademik dengan menggunakan indikator bibliometrik yang memperhitungkan baik volume maupun isi web, visibilitas, dan dampak dari publikasi web sesuai dengan jumlah pranala luar (external link) yang diterima.

Produk dari Webometrics adalah daftar peringkat universitas seluruh dunia yang dikeluarkan setiap enam bulan sekali, yaitu pada bulan Januari dan Juli. Pemeringkatan ini menjadi motivasi bagi perguruan tinggi untuk meningkatkan kualitas pendidikannya. Dengan pemeringkatan ini, calon mahasiswa pun diuntungkan untuk lebih cermat dalam memilih perguruan tinggi yang diinginkan. Selain itu, dengan pemeringkatan ini pihak universitas dapat lebih mudah untuk melakukan kerja sama dengan pihak asing.

Brand website merupakan alat pemasaran potensial dalam memberikan kesempatan yang kuat untuk memelihara hubungan pelanggan karena berakibat terhadap terciptanya peluang untuk meningkatkan potensi co-creation inovatif antara konsumen dan perusahaan (Mangold \& Faulds, 2009; Alden et al., 2016). Terdapat korelasi yang signifikan antara persepsi keseluruhan citra lembaga dan evaluasi elemen individu situs web lembaga (Manzoor et al., 2012). Aksesibilitas perangkat, realitas konten, individualisasi, mesin pencarian kata kunci, dan fungsi fitur identitas adalah lima prinsip media sosial yang paling signifikan dalam memenuhi kebutuhan pengguna (Hsieh, 2016).
Dalam konteks perguruan tinggi, kondisi-kondisi yang telah diuraikan di atas mengindikasikan bahwa website dapat dijadikan alat untuk menjadikan konsumen mengenal lebih jauh tentang perguruan tinggi dan produk-produknya. Selain itu, website dapat membangun potensi co-creation antara institusi dan para pemangku kepentingan. Dengan demikian desain dan fitur website berkontribusi terhadap efektivitas penyampaian pesan, kualitas produk dan jasa, dan brand image perguruan tinggi tersebut. Oleh karena itu, agar dapat difungsikan secara maksimal sebuah website harus dirancang sedemikian rupa sehingga menyenangkan, menarik, mudah dibaca, mudah digunakan, dan merangsang emosional para pemangku kepentingan untuk selalu mengunjungi website tersebut.

Penelitian tentang website perguruan tinggi telah dilakukan oleh beberapa peneliti. Dari aspek mahasiswa, terdapat penelitian tentang layanan dan informasi yang menarik bagi mahasiswa dan calon mahasiswa baru melalui website perguruan tinggi (Wilson \& Meyer, 2009) dan keinginan mahasiswa atau user dalam proses pembelajaran online (Lindquist \& Long, 2011). Dari aspek teknis, terdapat penelitian tentang pengelolaan situs web universitas (Cox \& Emmott, 2007), halhal yang harus selalu diperbarui oleh pengembang web universitas (Štefko et al., 2015), dan analisis untuk menciptakan kesadaran akan pentingnya aksesibilitas dan kriteria kegunaan situs web pendidikan tinggi di Malaysia (Aziz et al., 2010).

Web juga dapat meningkatkan citra lembaga. Penelitian terkait hal tersebut salah satunya tentang korelasi antara persepsi keseluruhan citra lembaga dan evaluasi elemen individu situs web lembaga (Manzoor et al., 2012). Selain itu, terdapat penelitian mengenai prinsip-prinsip media sosial yang paling signifikan dalam memenuhi kebutuhan pengguna (Hsieh, 2016).

Penelitian-penelitian yang telah diuraikan di atas lebih fokus kepada pengembangan dan pengelolaan website agar lebih menarik dan dapat 
diakses oleh mahasiswa normal dan penyandang difabel. Dalam pengembangan website selain mahasiswa tentu saja perlu diperhatikan pemangku kepentingan perguruan tinggi lainnya seperti pelajar atau calon mahasiswa, dosen, tenaga kependidikan, dan masyarakat luas. Disamping itu, untuk meningkatkan peringkat Webometrics, pengembangan website juga harus dilakukan dengan memperhatikan kriteria-kriteria yang digunakan oleh Webometrics dalam melakukan pemeringkatan.

Penelitian tentang kebutuhan konsumen yang tidak hanya terdiri dari mahasiswa terhadap isi maupun struktur website perguruan tinggi telah dilakukan oleh Indrianti dkk. (2013). Namun demikian, penelitian tersebut hanya terbatas pada suara konsumen (voice of customer, VOC). Meskipun dalam penelitian tersebut atribut VOC diturunkan dari indikator Webometrics 2012, namun VOC hasil penelitian belum diterjemahkan ke aspek teknis. Padahal, untuk meningkatkan kualitas website selain VOC juga perlu diperhatikan aspek atau dimensi teknis.

Kebaharuan penelitian ini dibanding dengan penelitian sebelumnya terlihat pada strategi yang digunakan dalam pengembangan website. Strategi pengembangan website menggunakan metode Quality Function Deployment (QFD). QFD pertama kali digunakan untuk memperbaiki perencanaan proses suatu barang di industri manufaktur di Jepang pada akhir tahun 1960an dan awal tahun 1970-an (Bouchereau \& Rowlands, 2000). Fungsi utama QFD adalah pengembangan produk, manajemen kualitas, dan analisis kebutuhan pelanggan. Aplikasi QFD sangat luas dan telah diterapkan di banyak sektor industri (Trappey et al., 2017). Proses QFD melibatkan empat fase, yaitu: perencanaan produk, desain produk, perencanaan proses, dan kontrol proses (Bouchereau \& Rowlands, 2000). Tahap terpenting pada QFD adalah penyusunan House of Quality (HOQ) pada fase perencanaan produk dan sebagai dasar fase desain produk. HOQ atau biasa disebut dengan rumah kualitas menggambarkan hubungan antara kebutuhan konsumen dengan karakteristik teknis, antar karakteristik teknis, dan nilai kepentingan absolut (absolute importance) untuk kebutuhan konsumen dan karakteristik teknis.

QFD dirasa tepat sebagai metode untuk menentukan strategi pengembangan website perguruan tinggi karena dapat mengintegrasikan aspek konsumen dan aspek teknis. Konsep dasar QFD adalah menerjemahkan keinginan konsumen ke dalam teknis yang tepat pada setiap langkah pengembangan produk seperti strategi pemasaran, perencanaan, perancangan produk, evaluasi prototype, pengembangan proses produksi, produksi, dan penjualan (Chan \& Wu, 2002). Dengan mengintegrasikan kebutuhan konsumen dan karakteristik teknis, website yang dikembangkan dengan metode QFD diharapkan dapat menjadi media IMC yang efektif sekaligus meningkatkan peringkat Webometrics.

Berdasarkan permasalahan di atas, penelitian ini bertujuan untuk menemukan strategi pengembangan website perguruan tinggi agar dapat menjadi alat komunikasi pemasaran terpadu yang efektif sekaligus untuk meningkatkan peringkat Webometrics. Pengembangan yang dimaksudkan di sini adalah perancangan website baru atau peningkatan kualitas website yang sudah ada. Untuk tujuan tersebut, strategi pengembangan website disusun berdasarkan kebutuhankonsumendankebutuhanteknisdengan memperhatikan indikator yang digunakan oleh Webometrics dalam melakukan pemeringkatan.

\section{Metode Penelitian}

Metode pengumpulan data bersifat kualitatif dan kuantitatif. Metode kuantitatif digunakan untuk mengidentifikasi VOC. Sedangkan metode kualitatif digunakan untuk menentukan strategi teknis, menyusun matriks hubungan antar karakteristik teknis, dan membuat hubungan antara kebutuhan konsumen dan karakteristik teknis. Analisis data dilakukan berdasarkan teknik reduksi data untuk VOC dan tampilan data untuk penentuan hubungan antar atribut. 
Penelitian ini merupakan exploratory research yang menggunakan konsep dasar QFD. Obyek penelitian adalah penggunaaan metode QFD untuk menentukan strategi pengembangan website perguruan tinggi, dengan subyek penelitian adalah website Universitas Pembangunan Nasional "Veteran" Yogyakarta.

HOQ yang terdiri dari enam bagian yang menggambarkan hubungan antar atribut dapat dilihat pada Gambar 1. Pada gambar tersebut dapat dilihat bahwa rencana strategis atau rencana pengembangan (Bagian B) ditentukan berdasarkan hubungan antara kebutuhan konsumen dan karakteristik teknis (Bagian D) dan prioritas karakteristik teknis (Bagian F).

Dalam penelitian ini karakteristik teknis ditentukan berdasarkan indikator pemeringkatan Webometrics, sedangkan kebutuhan dan keinginan konsumen (voice of customer, VOC) didasarkan pada hasil penelitian Indrianti dkk. (2013) yang menggunakan indikator Webometrics 2012. Indikator tersebut meliputi: 1) Size, yaitu jumlah halaman (selain rich files) yang ditemukan dari empat mesin pencari: Google, Yahoo, Live Search, dan Exalead (bobot 10\%); 2) Visibility, yaitu jumlah link eksternal yang diterima (inlinks) oleh sebuah situs (bobot 50\%); 3) Rich files, yaitu volume file yang ada pada situs perguruan tinggi atau universitas, dalam format yang dinilai layak (pdf, doc, ps,

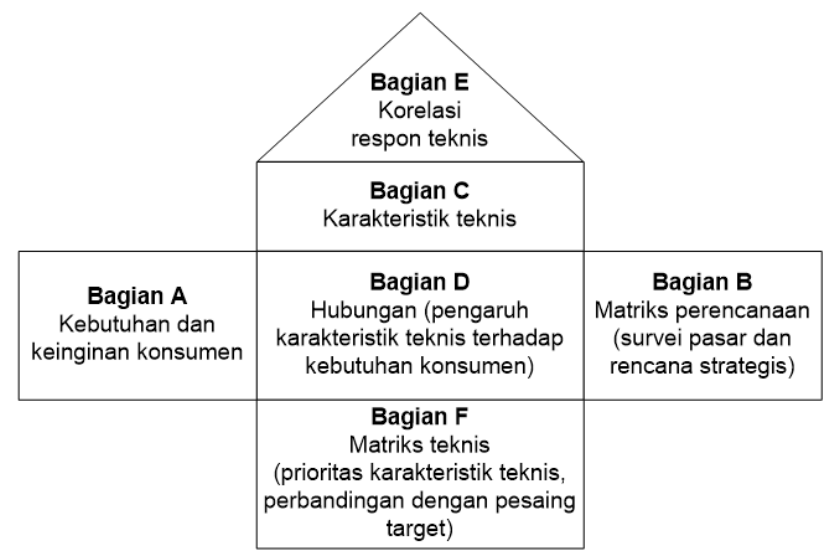

Gambar 1. Model House of Quality
Sumber: Wijaya (2011) dan ppt) (bobot 10\%); 4) Scholar, yaitu berisikan tulisan-tulisan ilmiah dan bersifat akademis yang diambil dari Google Scholar (bobot 30\%).

Penggunaan QFD untuk menentukan strategi pengembangan website dalam penelitian ini dilakukan dengan langkah-langkah berikut: 1) Mengidentifikasi VOC yang bertujuan untuk mendapatkan atribut-atribut yang diinginkan oleh stakeholders (para pemangku kepentingan). Pada tahap ini digunakan data penelitian Indrianti dkk. (2013) yang melibatkan 404 responden yang terdiri dari pelajar atau calon mahasiswa, mahasiswa, dan dosen dari seluruh Indonesia. Pengumpulan data dilakukan dengan teknik snowball sampling. Selain uji kecukupan data, dilakukan uji statistik terhadap kredibilitas dan realibilitas instrumen yang digunakan. Analisis data dilakukan dengan teknik reduksi data menggunakan Crosstabs atau tabulasi silang; 2) Menyusun House of Quality (HOQ), dengan langkah-langkah: a) menentukan strategi teknis; b) menyusun matriks hubungan antarkarakteristik teknis; c) membuat matriks hubungan antara kebutuhan konsumen dan karakteristik teknis; Langkah a, b, dan c pada tahap ini dilakukan berdasarkan hasil wawancara dengan dua orang pakar telematika Universitas Pembangungan Nasional "Veteran" Yogyakarta; d) Menghitung nilai target atau kepentingan absolut dari karakteristik teknis dengan persamaan berikut:

$$
\begin{aligned}
& A I_{j}=\sum_{i}^{N} \sum_{j}^{M} x_{i j} y_{i} \\
& \text { dengan: } \\
& A I_{j} \quad \text { : nilai kepentingan absolut karakteristik teknis } j \\
& x_{i j} \quad \text { : nilai hubungan antara kebutuhan } \\
& \text { konsumen } i \text { dengan karakteristik teknis } j \\
& (i=1, \ldots, N \text { dan } j=1, \ldots, M) \\
& y_{i} \quad: \quad \text { bobot global kebutuhan konsumen } i \\
& A I_{i}=\sum_{i=1}^{N} \sum_{j=1}^{M} y_{i j} x_{i j^{*}} \\
& \text { dengan: } \\
& A I_{i} \quad \text { : nilai kepentingan absolut kebutuhan konsumen } i \\
& x_{i j^{*}} \quad \text { : nilai hubungan antara kebutuhan } \\
& \text { konsumen } i \text { dengan karakteristik } \mathrm{t} \\
& \text { teknis terpilih per indikator Webometrics } j \\
& (i=1, \ldots, N \text { dan } j=1, \ldots, M)
\end{aligned}
$$


g)Menyusun matriks HOQ. 3) Penentuan strategi pengembangan website ditentukan berdasarkan kekuatan hubungan antar karakteristik teknis masing-masing atribut pada masing-masing dimensi dan antara karakteristik teknis dengan VOC.

\section{Hasil Penelitian dan Pembahasan VOC atau kebutuhan konsumen}

VOC dituangkan ke dalam dimensi informasi umum, konten, struktur, dan performansi sebagaimana ditunjukkan pada Tabel 1. Pada tabel tersebut dapat dilihat bobot lokal dan global setiap atribut. Bobot atribut lokal menunjukkan tingkat kepentingan sebuah atribut dibandingkan atribut lain dalam dimensi yang sama. Sedangkan bobot global menunjukkan tingkat kepentingan sebuah atribut dibandingkan tingkat kepentingan atribut lain secara keseluruhan pada semua dimensi. Berdasarkan bobot global dapat ditentukan prioritas masing-masing atribut (Tabel 1).

\section{House of Quality (HOQ) Strategi teknis}

Penentuan strategi teknis ditetapkan berdasarkan kebutuhan pelanggan pada Tabel 1 dengan memperhatikan pendapat pakar telematika. Hasilnya ditunjukkan pada Tabel 2. Dari tabel tersebut dapat dilihat upayaupaya teknis yang dapat dilakukan untuk meningkatkan mutu masing-masing dimensi. Mengacu kepada hasil penelitian pada Tabel 1, pada indikator Rich files terlihat bahwa tidak hanya karya ilmiah dan artikel akademis yang harus dipublikasi, namun juga semua dokumen yang pantas untuk dipublikasi.

Tabel 2. Strategi Teknis

\begin{tabular}{ccl}
\hline Indikator & No. & \multicolumn{1}{c}{ Karakteristik Teknis } \\
\hline & 1 & Menambah jumlah halaman \\
Size & 2 & $\begin{array}{l}\text { Mengusahakan search engine yang mudah digunakan } \\
\text { (user friendly) }\end{array}$ \\
& 3 & $\begin{array}{l}\text { Membuat } \text { web baru } \\
\text { Visibility }\end{array}$ \\
& 4 & Meningkatkan kualitas konten \\
& 6 & Promosi website \\
& 7 & Meningkatkan link \\
& & Mengusahakan semua konten dalam format html \\
& 8 & Meningkatkan upload artikel dalam format pdf, doc, \\
Rich files & & ppt, dan ps \\
& 9 & Digitalisasi dan publikasi dokumen \\
Scholar & 10 & Digitalisasi dan publikasi karya ilmiah dan artikel \\
& & akademik \\
\hline
\end{tabular}

Tabel 1. Kebutuhan Konsumen Website

\begin{tabular}{|c|c|c|c|c|c|c|}
\hline No & Dimensi & No. Atribut & Deskripsi & $\begin{array}{c}\text { Bobot atribut per } \\
\text { dimensi }\end{array}$ & $\begin{array}{l}\text { Bobot } \\
\text { global }\end{array}$ & Prioritas \\
\hline \multirow[t]{5}{*}{ T } & \multirow[t]{5}{*}{ Tnformasi Umum } & T.1. & Hiburan & 0,324 & 0,0736 & 3 \\
\hline & & 1.2. & Berita & 0.287 & 0,0652 & 5 \\
\hline & & 1.3. & IPTEK & 0,280 & 0,0636 & 6 \\
\hline & & 1.4. & Life siyle & 0,059 & 0,0134 & 15 \\
\hline & & 1.5. & $\begin{array}{l}\text { Lain-lain (olahraga, rohani, } \\
\text { lowongan kerja dil.) }\end{array}$ & 0,050 & 0,0114 & 17 \\
\hline \multirow[t]{8}{*}{2} & \multirow{8}{*}{$\begin{array}{l}\text { Kontea Perguruan } \\
\text { Tinggi }\end{array}$} & 2.1. & Profil & 0,151 & 0,0618 & 7 \\
\hline & & 2.2. & Fasilitas & 0,121 & 0,0495 & 9 \\
\hline & & 2.3. & Berita & 0,099 & 0,0405 & 14 \\
\hline & & 2.5 . & Infoommasi akadamik & 0,423 & 0,1730 & 1 \\
\hline & & 2.6. & Oryanisasi kemahasiswaan & 0,025 & 0,0102 & 18 \\
\hline & & 2.7. & Galeni & 0,022 & 0,0090 & 19 \\
\hline & & 2.8. & Media onitne & 0,030 & 0,0123 & 16 \\
\hline & & 2.9. & Layanen interaktif & 0,020 & 0,0082 & 20 \\
\hline \multirow[t]{5}{*}{3} & \multirow{5}{*}{$\begin{array}{l}\text { Elemen Struktur } \\
\text { Wachsite }\end{array}$} & 3.1 . & Aksesibilitas & 0,317 & 0,0720 & 4 \\
\hline & & 3.2 . & Desain & 0.208 & 0,0473 & 10 \\
\hline & & 3.3. & Koaten & 0,260 & 0,0591 & 8 \\
\hline & & 3.4. & $\begin{array}{l}\text { Penyajian (display) atau } \\
\text { presentasi }\end{array}$ & 0,198 & 0,0450 & 12 \\
\hline & & 3.5. & $\begin{array}{l}\text { Lain-lain (user friendly dan } \\
\text { lain-lain) }\end{array}$ & 0,017 & 0,0039 & 21 \\
\hline \multirow[t]{3}{*}{4} & \multirow{3}{*}{$\begin{array}{l}\text { Performansi } \\
\text { Widsite }\end{array}$} & 4.1. & Time to load (kecopatan) & 0,678 & 0,0925 & 2 \\
\hline & & 4.2. & $\begin{array}{l}\text { Search engine aptimization } \\
\text { (SEO) }\end{array}$ & 0.312 & 0,0425 & 13 \\
\hline & & 4.3. & Lain-lain (keduanya) & 0.010 & 0,0014 & 22 \\
\hline
\end{tabular}

Sumber: Indrianti et.all (2013) 
Matriks hubungan antar karakteristik teknis

Hubungan antar karakteristik teknis ditentukan berdasarkan pendapat pakar telematika perguruan tinggi melalui wawancara. Data hasil wawancara ditampilkan dalam bentuk matriks hubungan antar atribut sebagaimana ditunjukkan pada Gambar 2 .

Sebuah karakteristik teknis yang memiliki hubungan kuat dengan karakteristik lain berarti menjadi bagian dari upaya peningkatan karakteristik tersebut. Sebagai contoh, pada indikator Size meningkatkan kualitas konten (No. 4) merupakan salah satu upaya menjadikan search engine menjadi mudah digunakan (No. 2). Pada indikator Visibility meningkatkan unggah artikel dalam format pdf, doc, ppt, dan ps (No. 8) merupakan bagian dari peningkatan link (No. 6). Karakteristik teknis "Digitalisasi dan publikasi karya ilmiah dan artikel akademik" (No.10) mempunyai hubungan yang kuat dengan "Mengusahakan konten dalam format html dan bisa diunduh dalam format pdf" (No.7) dan "Meningkatkan unggah dalam format pdf, doc, ppt, dan ps" (No.8). Ketiga karakteristik tersebut berkesinambungan dan saling mempengaruhi.

\section{Matriks Hubungan Antara Kebutuhan \\ Konsumen Dan Karakteristik Teknis}

Pada tahap ini juga dilakukan wawancara dengan pakar telematika perguruan tinggi. Hasilnya ditampilkan pada Gambar 3. Nilai target atau kepentingan absolut dari karakteristik teknis, dihitung menggunakan Persamaan (1). Prioritas per indikator karakteristik teknis karena setiap indikator memiliki kepentingan yang besar dalam pengukuran Webometrics, maka semua indikator harus diikutkan dalam upaya peningkatan peringkat Webometrics. Oleh karena itu, prioritas ditentukan untuk setiap indikator. Kepentingan absolut untuk kebutuhan konsumen, dihitung menggunakan Persamaan (2). Matriks HOQ yang disusun berdasarkan hasil langkah (a) sampai dengan (f) dapat dilihat pada Gambar 4. Pada gambar tersebut nilai kepentingan absolut karakteristik teknis berada pada bagian bawah, sedangkan nilai kepentingan absolut kebutuhan konsumen berada pada bagian kanan.

Indikator Scholar hanya memiliki satu karakteristik teknis, yaitu "digitalisasi karya ilmiah dan artikel akademik". Oleh karena itu, karakteristik ini langsung menjadi prioritas sebagai upaya peningkatan peringkat Webometrics pada indikator Scholar.

Nilai target atau kepentingan absolut dari karakteristik teknis, dihitung menggunakan Persamaan (1). Prioritas per indikator karakteristik teknis karena setiap indikator memiliki kepentingan yang besar dalam pengukuran Webometrics, maka semua indikator harus diikutkan dalam upaya peningkatan peringkat Webometrics. Oleh karena itu, prioritas ditentukan untuk setiap indikator. Kepentingan absolut untuk kebutuhan konsumen, dihitung menggunakan Persamaan (2). Matriks HOQ

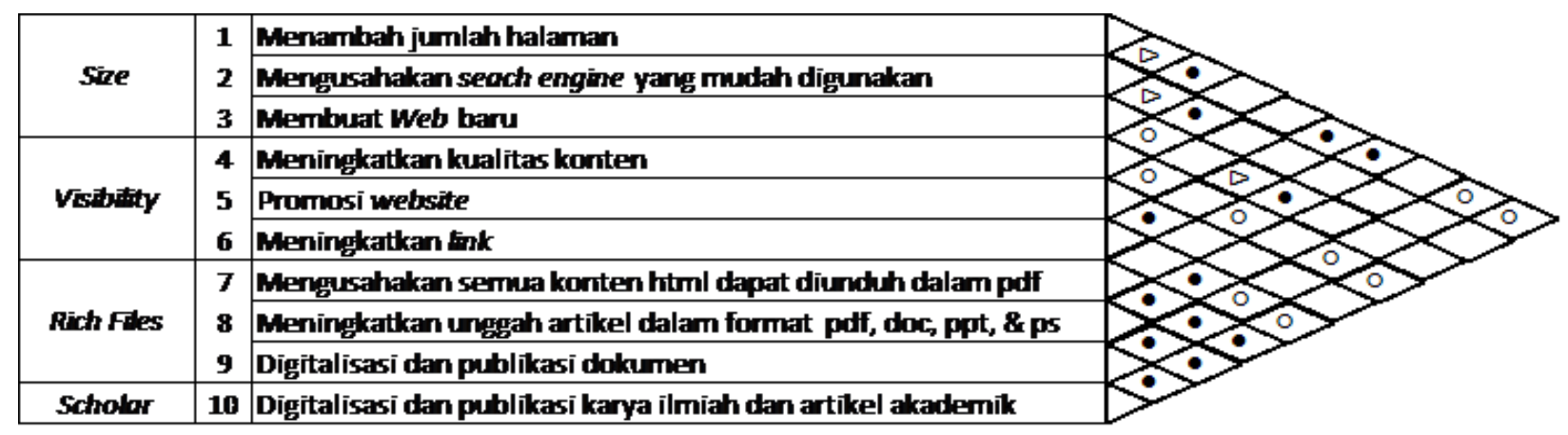

Keterangan: •: hubungan kuat (nilai 9), ○: hubungan sedang (nilai 3),

$\Delta$ : hubungan lemah (nilai 1), tidak ada tanda (kosong): tidak ada hubungan (nilai 0 ) Gambar 2. Matriks Hubungan Antar Karakteristik Teknis

Sumber: Hasil Olahan Peneliti (2019) 


\begin{tabular}{|c|c|c|c|c|c|c|c|c|c|c|c|}
\hline \multirow{2}{*}{\multicolumn{2}{|c|}{$\begin{array}{l}\text { Kebutuhan } \\
\text { konsumen }\end{array}$}} & \multicolumn{3}{|c|}{ Size } & \multicolumn{3}{|c|}{ Visibility } & \multicolumn{3}{|c|}{ Rich files } & \multirow{2}{*}{$\begin{array}{c}\begin{array}{c}\text { Scholar } \\
\text { ship }\end{array} \\
10\end{array}$} \\
\hline & & 1 & 2 & 3 & 4 & 5 & 6 & 7 & 8 & 9 & \\
\hline \multirow{5}{*}{$\begin{array}{l}\text { 1. Dimensi } \\
\text { informasi umum }\end{array}$} & 1.1 & $\bullet$ & $\bullet$ & $\bullet$ & $\bullet$ & & $\bullet$ & $\bullet$ & $\bullet$ & $\bullet$ & \\
\hline & 1.2 & $\bullet$ & $\bullet$ & $\bullet$ & $\bullet$ & & $\bullet$ & $\bullet$ & $\bullet$ & $\bullet$ & \\
\hline & 1.3 & $\bullet$ & $\bullet$ & $\bullet$ & $\bullet$ & & $\bullet$ & $\bullet$ & $\bullet$ & $\bullet$ & \\
\hline & 1.4 & $\bullet$ & $\bullet$ & $\Delta$ & $\Delta$ & & $\bullet$ & $\bullet$ & $\bullet$ & $\bullet$ & \\
\hline & 1.5 & $\bullet$ & $\bullet$ & $\Delta$ & $\Delta$ & & $\bullet$ & $\bullet$ & $\bullet$ & $\bullet$ & \\
\hline \multirow{9}{*}{$\begin{array}{l}\text { 2. Dimensi konten } \\
\text { web perguruan } \\
\text { tinggi }\end{array}$} & 2.1 & $\bullet$ & $\bullet$ & $\circ$ & 0 & & $\bullet$ & $\bullet$ & $\bullet$ & $\bullet$ & \\
\hline & 2.2 & $\bullet$ & $\bullet$ & $\circ$ & 0 & & $\bullet$ & $\bullet$ & $\bullet$ & $\bullet$ & \\
\hline & 2.3 & $\bullet$ & $\bullet$ & $\circ$ & $\circ$ & & $\bullet$ & $\bullet$ & $\bullet$ & $\bullet$ & \\
\hline & 2.4 & $\bullet$ & $\bullet$ & $\circ$ & $\circ$ & & $\bullet$ & $\bullet$ & $\bullet$ & $\bullet$ & \\
\hline & 2.5 & $\bullet$ & $\bullet$ & $\bullet$ & $\bullet$ & & $\bullet$ & $\bullet$ & $\bullet$ & $\bullet$ & \\
\hline & 2.6 & $\bullet$ & $\bullet$ & $\Delta$ & $\Delta$ & & $\bullet$ & $\bullet$ & $\bullet$ & $\bullet$ & $\bullet$ \\
\hline & 2.7 & $\bullet$ & $\bullet$ & $\Delta$ & $\Delta$ & $\bullet$ & $\bullet$ & & & & \\
\hline & 2.8 & $\bullet$ & $\bullet$ & $\Delta$ & $\Delta$ & & $\bullet$ & & $\bullet$ & $\bullet$ & $\bullet$ \\
\hline & 2.9 & $\bullet$ & $\bullet$ & $\Delta$ & $\Delta$ & $\bullet$ & $\bullet$ & & & $\bullet$ & $\bullet$ \\
\hline \multirow{5}{*}{$\begin{array}{l}\text { 3. Dimensi struktur } \\
\text { web }\end{array}$} & 3.1 & & $\bullet$ & $\bullet$ & 0 & & $\bullet$ & $\Delta$ & & $\Delta$ & $\Delta$ \\
\hline & 3.2 & & & $\circ$ & & & & & & $\Delta$ & $\Delta$ \\
\hline & 3.3 & $\bullet$ & $\bullet$ & $\bullet$ & $\bullet$ & $\bullet$ & $\bullet$ & $\bullet$ & $\bullet$ & $\bullet$ & $\circ$ \\
\hline & 3.4 & & $\bullet$ & $\bullet$ & $\bullet$ & & & & & $\circ$ & 0 \\
\hline & 3.5 & & $\circ$ & $\circ$ & & & & & & & \\
\hline \multirow{3}{*}{$\begin{array}{l}\text { 4. Dimensi website } \\
\text { performance }\end{array}$} & 4.1 & & & $\bullet$ & & & & & & & \\
\hline & 4.2 & $\bullet$ & $\bullet$ & $\bullet$ & $\bullet$ & $\bullet$ & $\bullet$ & & & & \\
\hline & 4.3 & $\circ$ & 0 & $\bullet$ & 0 & 0 & $\circ$ & & & & \\
\hline
\end{tabular}

Gambar 3. Matriks Hubungan Kebutuhan

Konsumen dengan Karakteristik Teknis Sumber: Hasil olahan peneliti (2019) yang disusun berdasarkan hasil langkah (a) sampai dengan (f) dapat dilihat pada Gambar 4. Pada gambar tersebut nilai kepentingan absolut karakteristik teknis berada pada bagian bawah, sedangkan nilai kepentingan absolut kebutuhan konsumen berada pada bagian kanan.

Indikator Scholar hanya memiliki satu karakteristik teknis, yaitu "digitalisasi karya ilmiah dan artikel akademik". Oleh karena itu, karakteristik ini langsung menjadi prioritas sebagai upaya peningkatan peringkat Webometrics pada indikator Scholar.

\section{Penentuan strategi}

Berdasarkan HOQ yang ditunjukkan pada Gambar 4 dapat diketahui karakteristik teknis prioritas dan karakteristik lain serta VOC yang terhubung kuat sebagaimana disajikan pada Tabel 3. Dari sini dapat ditentukan strategi pengembangan secara keseluruhan.

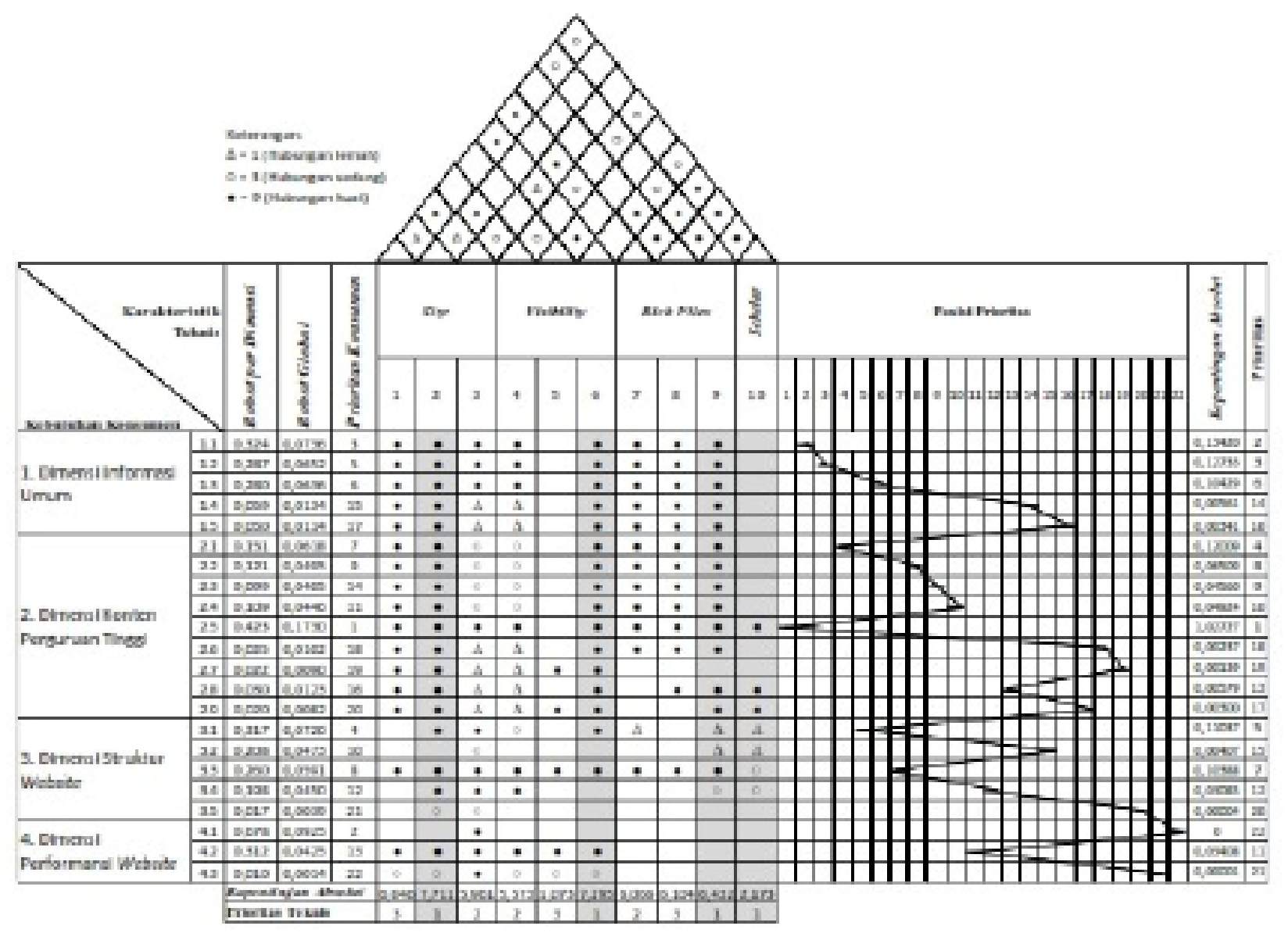

Gambar 4. HOQ Rancangan Website Perguruan Tinggi 
Tabel 3. Karakteristik Teknis Prioritas dan Karakteristik Lain serta VOC yang Terhubung Kuat

\begin{tabular}{|c|c|c|c|}
\hline \multirow{2}{*}{ Indikator } & \multicolumn{2}{|c|}{ Karakteristik teknis } & \multirow{2}{*}{ VOC yang terhubung kuat } \\
\hline & Pricritas & Berhubungan kuat dengan & \\
\hline $\begin{array}{l}\text { Size } \\
(10 \%)\end{array}$ & $\begin{array}{l}\text { (2) Mengusahakan rearch } \\
\text { cwgine yang mudah } \\
\text { digunakan }\end{array}$ & (4) Menindkatkan kualitas koeten & $\begin{array}{l}\text { - Seluruh barakieristili dimensi informasi umum } \\
\text { - Scluruh karakicristik dimensi Konten } \\
\text { * (3.1) Meningkatkan aksesibilitas } \\
\text { * (3.3) Meningkatkan komen } \\
\text { * (3.4) Meningkutkan Penyajian (dilisplay) } \\
\text { - (4.2) Optimaxi search engine (SEO) }\end{array}$ \\
\hline $\begin{array}{c}\text { Visibility } \\
(50 \%)\end{array}$ & (6) Mcningkatkan tink & $\begin{array}{l}\text { (8) Meningkatkan ungeah artikcl } \\
\text { dalam format pdf, doc, ppt, dan ps }\end{array}$ & $\begin{array}{l}\text { - Seluruh karakieristik dimensi informasi umum } \\
\text { * Seluruh bankteristili dimensi Konten } \\
\text { * (3.1) Meningkatkan aksesibilitas } \\
\text { * (3.3) Meningkatkan konten } \\
\text { - (4.2) Optimasi seanch evgine (SEO) }\end{array}$ \\
\hline $\begin{array}{l}\text { Rich files } \\
(10 \%)\end{array}$ & $\begin{array}{l}\text { (9) Digitalisasi dan publikasi } \\
\text { dokumen }\end{array}$ & $\begin{array}{l}\text { (9) Digitalisasi dan publikasi karya } \\
\text { ilmiah dan artikel abadkmik }\end{array}$ & $\begin{array}{l}\text { - Seluruh karakieristik dimensi informasi umum } \\
\text { - Seluruh karakieristik dimensi konten, kecuali } \\
\text { galeni } \\
\text { - (3.3) Meningkatkan komen }\end{array}$ \\
\hline $\begin{array}{l}\text { Schalar } \\
(3055)\end{array}$ & $\begin{array}{l}\text { (10) Digitalisasi karya ilmish } \\
\text { dan artikel akademik }\end{array}$ & $\begin{array}{l}\text { (7) Mengusahakan konten html dupat } \\
\text { diundah dalam format pdf } \\
\text { (8) Meninekatkan ungutah artikel } \\
\text { dalam format pdf, doc, ppt, dan ps } \\
\text { (9) Digitalisasi dan publikasi dokumen }\end{array}$ & $\begin{array}{l}\text { - (2.6) Meningkatkan konten organisasi } \\
\text { kemahasiswaan } \\
\text { * (2.8) Meningkatkan media ouline } \\
\text { * (2.9) Meningkatkan layanan interaktif } \\
\text { - (3.1) Meningkatkan aksesibilitas }\end{array}$ \\
\hline
\end{tabular}

Sumber: Hasil analisis peneliti (2019)

Tabel 3 menunjukkan bahwa dilihat dari bobot indikator, prioritas strategi yang sebaiknya dilakukan adalah meningkatkan link, digitalisasi karya ilmiah dan artikel akademik, mengusahakan search engine yang mudah digunakan, dan digitalisasi dan publikasi dokumen. Memperhatikan karakteristik teknis lain dan VOC yang berhubungan kuat, diusulkan langkah-langkah peningkatan website guna meningkatkan peringkat Webometrics sebagai berikut: 1) Digitalisasi karya ilmiah dan artikel akademik dan menggunggahnya dalam format pdf, doc, ppt, dan ps; 2) Optimasi search engine (SEO); 3) Mengusahakan konten html dapat diunduh dalam format pdf; 4) Meningkatkan konten informasi sesuai kebutuhan konsumen; 5) Meningkatkan struktur website yang meliputi akasesibilitas, penyajian (display), media online, dan layanan interaktif.

Prioritas informasi yang dibutuhkan oleh konsumen ditentukan berdasarkan kepentingan absolut, sebagaimana ditunjukkan pada Gambar 4, yaitu yang berkaitan dengan: (2.5) akademik, (1.1) hiburan, (1.2) profil perguruan tinggi, (1.3) IPTEK, (2.2) fasilitas perguruan tinggi, (2.3) penerimaan mahasiswa baru, (2.4) berita, (1.4) life style atau gaya hidup, (1.5) Lain-lain (olahraga, rohani, lowongan kerja d1l.), dan (2.6) organisasi kemahasiswaan. Artikel akademik dapat berupa pengetahuan, penelitian, dan informasi akademik, khususnya kalender akademik dan silabus matakuliah.

Hasil penelitian menunjukkan bahwa metode QFD dapat digunakan untuk menentukan strategi pengembangan website perguruan tinggi secara efektif dan efisien. Dengan metode tersebut website perguruan tinggi dapat dirancang untuk menyediakan informasi sesuai kebutuhan konsumen atau pemangku kepentingan sekaligus memenuhi indikator penilaian Webometrics. Dengan demikian, target pasar dan peringkat Webometrics dapat dicapai secara bersamaan.

Strategi yang diusulkan dalam penelitian ini dapat mengantarkan website sebagai alat promosi yang efektif bagi sebuah perguruan tinggi. Melalui Dimensi Konten, perguruan tinggi dapat menyampaikan pesan-pesan kepada pemangku kepentingan terkait dengan profil, kegiatan akademik, kegiatan mahasiswa, dan lain-lain, baik yang bersifat informasi biasa, promosi, iklan, atau penjualan produk-produk perguruan tinggi. Kondisi ini menegaskan 
bahwa website dapat menjadi bagian penting dari strategi IMC sebagaimana dinyatakan oleh Mangold dan Faulds (2009), Finne dan Grönroos (2017), dan Kumar dan Nanda (2018).

Strategi peningkatan konten informasi yang berkaitan dengan artikel akademik dapat meningkatkan fungsi website sebagai media pendukung proses pendidikan. Hal ini sejalan dengan pendapat Manzoor et al. (2012), Kousha dan Thelwall (2008), dan Thelwall dan Kousha (2008) bahwa website merupakan bagian penting dari proses pendidikan tinggi. Selain untuk meningkatkan mutu pembelajaran, website dapat dimanfaatkan untuk mengkomunikasikan karya ilmiah sivitas akademika kepada publik sehingga dapat meningkatkan publisitas atau citra lembaga.

Aksesibilitas merupakan salah satu prinsip media sosial yang signifikan bagi konsumen (Hsieh, 2016). Oleh karena itu, selain peningkatan konten, optimasi SEO dan peningkatan struktur website yang diusulkan dalam penelitian ini juga merupakan hal penting. Kedua strategi tersebut akan menjadikan website lebih menarik dan user friendly dengan kecepatan akses yang tinggi. Dengan demikian akan semakin banyak konsumen yang mengunjungi website tersebut dan diharapkan dapat meningkatkan minat beli konsumen.

Strategi peningkatan layanan interaktif dapat menjadi bagian dari fase keempat QFD, yaitu kontrol proses. Melalui fitur ini perguruan tinggi dapat meningkatkan mutu website secara berkelanjutan sesuai kebutuhan konsumen. Pelayanan interaktif yang cepat, responsif, dan customized merupakan modal yang siginifikan untuk membangun hubungan yang baik dengan konsumen. Sebagaimana dinyatakan oleh Mangold dan Faulds (2009) dan Alden et al. (2016), hubungan yang baik dengan konsumen memiliki potensi menciptakan menciptakan cocreation (kreasi bersama) antara perguruan tinggi dan pemangku kepentingan.
Dalam penelitian ini penyusunan HOQ didasarkan pada data kebutuhan konsumen hasil penelitian Indrianti dkk. (2013) yang diturunkan dari indikator penilaian Webometrics 2012. Namun demikian, langkah-langkah yang diusulkan dalam penelitian ini dapat diterapkan untuk menentukan strategi pengembangan website perguruan tinggi yang tidak hanya terbatas pada indikator Webometrics 2012 saja, namun juga Webometrics versi terakhir atau versi lain yang diinginkan. Selain itu, perguruan tinggi dapat menentukan prioritas strategi sesuai situasi dan kondisi, khususnya berdasarkan musim dan sasaran. Pada saat penerimaan mahasiswa baru, maka sasaran yang diprioritaskan adalah pelajar, yaitu dengan memperbanyak informasi tentang hal-hal yang terkait dengan penerimaan mahasiswa baru, pengenalan program studi. Pertimbangan-pertimbangan khusus seperti ini dapat dilakukan untuk mengatasi keterbatasan kapasitas pada website perguruan tinggi.

\section{Simpulan}

Persaingan lembaga pendidikan tinggi yang semakin kompetitif menuntut adanya strategi promosi yang tepat. Telah banyak diakui bahwa komunikasi pemasaran terpadu(IMC)merupakan strategi pemasaran yang efektif. Seiring dengan meluasnya penggunaan media sosial sebagai sumber informasi, beberapa pakar mengusulkan media sosial sebagai bagian dari strategi IMC organisasi. Perguruan tinggi telah menjadikan media dalam jaringan (daring), khususnya website, untuk mendukung kegiatan akademik dan promosi. Website juga menjadi salah satu dasar pemeringkatan universitas tingkat dunia yang dilakukan oleh Webometrics. Dengan latar belakang tersebut, penelitian ini dimaksudkan untuk menentukan strategi pengembangan website perguruan tinggi agar dapat menjadi media IMC yang efektif sekaligus meningkatkan peringkat Webometrics. Penggunaan metode QFD, yang mengintegrasikan suara konsumen 
dan aspek teknis, dari penelitian ini dihasilkan strategi pengembangan website perguruan tinggi yang tidak hanya menekankan aspek konten namun juga aspek teknis seperti aksesibilitas, SEO, display, dan layanan interaktif. Strategi yang demikian selain dapat meningkatkan efektivitas website perguruan tinggi sebagai media IMC, juga dapat meningkatkan mutu website secara berkelanjutan sesuai kebutuhan konsumen. Dengan mengakomodasikan indikator pemeringkatan Webometrics sebagai dasar penentuan karakteristik teknis, strategi yang dihasilkan dalam penelitian ini juga diharapkan dapat meningkatkan peringkat Webometrics perguruan tinggi.

Langkah-langkah pengembangan website yang diusulkan dalam penelitian ini dapat digunakan untuk mengembangkan website pada umumnya dengan memperhatikan dimensi mutu website yang dikembangkan. Dalam penelitian ini VOC ditentukan berdasarkan suara pelajar, mahasiswa, dan dosen. Mengingat bahwa pemangku kepentingan perguruan tinggi bukan hanya berasal dari kalangan akademisi, penelitian selanjutnya dapat diperluas dengan mengakomodasikan responden yang berasal dari industri, pemerintah, dan masayarakat pada umumnya. Penelitian ini juga merekomendasikan kepada perguruan tinggi lain ataupun instansi lain agar mengembangkan website sesuai dengan mutu website yang dikembangkan sesuai dengan kebutuhan konsumen.

\section{Daftar Pustaka}

Ailawadi, K. L., Beauchamp, J. P., Donthu, N., Gauri, D. K., \& Shankar, V. (2009). Communication and Promotion Decisions in Retailing: A Review and Directions for Future Research. Journal of Retailing. https://doi.org/10.1016/j.jretai.2008.11.002

Alden, D. L., Kelley, J. B., Youn, J. B., \& Chen, Q. (2016). Understanding Consumer Motivations to Interact on Brand Websites in The International Marketplace: Evidence from the U.S., China, and South Korea. Journal of Business Research. https://doi. org/10.1016/j.jbusres.2016.04.108

Aziz, M. A., Wan Mohd Isa, W. A. R., \& Nordin, N. (2010). Assessing The Accessibility and Usability of Malaysia Higher Education Website. Proceedings - 2010 International Conference on User Science and Engineering, i-USEr 2010. https://doi. org/10.1109/IUSER.2010.5716752

Belch, G. E., \& Belch, M. A. (2007). Advertising and Promotion: An Integrated Marketing Communications Perspective (7th ed.). McGraw-Hill.

Boone, L. E., \& Kurtz, D. L. (2007). Contemporary Marketing (13th ed.). SouthWestern Cengage Learning.

Bouchereau, V., \& Rowlands, H. (2000). Methods and Techniques to Help Quality Function Deployment (QFD). Benchmarking: An International Journal. https://doi. org/10.1108/14635770010314891

Chan, L. K., \& Wu, M. L. (2002). Quality Function Deployment: A Literature Review. European Journal of Operational Research. https:// doi.org/10.1016/S0377-2217(02)00178-9

Cox, A., \& Emmott, S. (2007). A survey of UK University Web Management: Staffing, Systems and Issues. CampusWide Information Systems. https://doi. org/10.1108/10650740710835742

Finne, A., \& Grönroos, C. (2017). Communication-In-Use: CustomerIntegrated Marketing Communication. European Journal of Marketing. https://doi. org/10.1108/EJM-08-2015-0553

Foux, G. (2006). Consumer-Generated Media: Get your Customers Involved. Brand Strategy.

Hsieh, M. Y. (2016). The Most Potential Principles of Social Media. Computers and Electrical Engineering. https://doi. org/10.1016/j.compeleceng.2015.12.013

Hsu, C. L., Chang, K. C., \& Chen, M. C. (2012). 
The Impact of Website Quality on Customer Satisfaction and Purchase Intention: Perceived Playfulness and Perceived Flow as Mediators. Information Systems and E-Business Management. https://doi. org/10.1007/s10257-011-0181-5

Indrianti, N., Rizqullah, A., \& Rustamaji, H. C. (2013). Analisis Kebutuhan Pengguna Website Perguruan Tinggi. Seminar Nasional Sains Dan Teknologi Terapan "SNTEKPAN" 2013.

Keegan, W. J., \& Green, M. C. (2008). Global Marketing. Prentice Hall.

Kousha, K., \& Thelwall, M. (2008). Assessing the Impact of Disciplinary Research on Teaching: an Automatic Analysis of Online Syllabuses. Journal of the American Society for Information Science and Technology. https://doi.org/10.1002/asi.20920

Kumar, V., \& Nanda, P. (2018). Social Media in Higher Education. International Journal of Information and Communication Technology Education. https://doi.org/10.4018/ ijicte. 2019010107

Lindquist, T., \& Long, H. (2011). How Can Educational Technology Facilitate Student Engagement With Online Primary Sources?: A User Needs Assessment. Library Hi Tech. https://doi.org/10.1108/07378831111138152

Mangold, W. G., \& Faulds, D. J. (2009). Social Media: The New Hybrid Element Of The Promotion Mix. Business Horizons. https:// doi.org/10.1016/j.bushor.2009.03.002

Manzoor, M., Hussain, W., Ahmed, A., \& Iqbal, M. J. (2012). The Importance of Higher Education Website and its Usability. International Journal of Basic and Applied Sciences. $\quad$ https://doi.org/10.14419/ijbas. v1i2.73
Pucciarelli, F., \& Kaplan, A. (2016). Competition and Strategy in Higher Education: Managing Complexity and Uncertainty. Business Horizons. $\quad$ https://doi.org/10.1016/j. bushor.2016.01.003

Rashtchy, F., Kessler, A. M., Bieber, P. J., Shindler, N. H., \& Tzeng, J. C. (2007). The User Revolution: The New Advertising Ecosystem and the Rise of the Internet as a Mass Medium. Piper Jaffray Investment Research.

Scott, D. M. (2015). The New Rules of Marketing and $P R$ (5th ed.). John Wiley \& Sons.

Shankar, V., \& Hollinger, M. (2007). Online and Mobile Advertising: Current Scenario, Emerging Trends, and Future Directions. Marketing Science Institute Special Report, $1-47$.

Simões, C., \& Soares, A. M. (2010). Applying to Higher Education: Information Sources and Choice Factors. Studies in Higher Education. https://doi. org/10.1080/03075070903096490

Štefko, R., Fedorko, R., \& Bačík, R. (2015). The Role of E-marketing Tools in Constructing the Image of a Higher Education Institution. Procedia - Social and Behavioral Sciences. $\quad$ https://doi.org/10.1016/j. sbspro.2015.01.1220

Thelwall, M., \& Kousha, K. (2008). Online Presentations as a Source of Scientific Impact? An Analysis of PowerPoint Files Citing Academic Journals. Journal of the American Society for Information Science and Technology. https://doi.org/10.1002/ asi.20803

Trappey, A. J. C., Trappey, C. V., Fan, C. Y., \& Lee, I. J. Y. (2017). Mining the Customer's Voice and Patent Data for Strategic Product 
Quality Function Deployment. Advances in Transdisciplinary Engineering. https://doi. org/10.3233/978-1-61499-779-5-985

Vollmer, C., \& Precourt, G. (2008). Always on: Advertising, Marketing, and Media in an Era of Consumer Control. McGraw-Hill.

Webometrics. (2018). Ranking Web of Universities. http://www.webometrics.info/

\section{en/About_Us}

Wijaya, T. (2011). Manajemen Kualitas Jasa. PT Indeks.

Wilson, J. L., \& Meyer, K. A. (2009). Higher Education Websites: The "Virtual Face" of Diversity. Journal of Diversity in Higher Education. https://doi.org/10.1037/ a0015443 